\title{
Research on Continued Use of Sport-related Social Application: Taking WeRun as an Example
}

\author{
Ke Zhang ${ }^{1, *}$, Yiqian Melannie Zhan ${ }^{2}$ \\ ${ }^{1}$ (first author) School of Communication, Hong Kong Baptist University, China \\ ${ }^{2}$ (second author) School of Communication, Hong Kong Baptist University, China
}

Copyright $@ 2017$ by authors, all rights reserved. Authors agree that this article remains permanently open access under the terms of the Creative Commons Attribution License 4.0 International License

\begin{abstract}
Research on healthcare gadget or application is not new to many of us, yet WeRun's special features have been a reason, and it is completely free of charge. While we take into consideration that WeRun is the most popular application in the world, this study makes a through exploration of how this application could attract loyal members and recruit new members every day. Based on the Theory of Expectation Confirmation, the research combing the variables of emotional pleasure and subjective norm into the expectation-confirmation model of IS continuance (ECM-ISC) to measure the factors that affect the continued use of WeRun by users. A 325 online questionnaire survey had been conducted to this research. The results show that emotional pleasure was positively and significantly associated with users' satisfaction of WeRun and internal influence was positively and significantly associated with users' continuance intention. However, emotional pleasure is not significantly associated with users' continuance intention and external influence has negative influence on user's continuance intention.
\end{abstract}

Keywords Social Application, Continuance Intention, Emotional Pleasure, Subjective Norm

\section{Introduction}

Research on continued use of communication technology has been a hot topic in past decades. The existing literature mainly focused on the functional satisfaction provided by communication technology for users but seldom explored how emotional factors exert influence on continued usage of communication technology. Emotional factors of users as well as subjective norm from personal relationships should not be ignore as they play important role in affecting the usage especially continued use of technological applications.

WeRun, a public account of WeChat (the most common used social media platform and communication technology among Chinese users), provides an option for people with fitness tracker devices or certain phones that can do motion tracking to share the number of steps they take each day.

This paper tries to exam the influence of emotional factors and subjective norm on the continued used of WeRun based on the Expectation Confirmation Theory. The significance of the research is that it supplies empirical data for the subsequent studies on social applications and provides a deep and comprehensive understanding of the complex factors that influence the intention and behavior of users in the continued use of social applications. Moreover, the study is also helpful in developing and improving the functions of the social media applications that meet the increasing demands of users.

\section{WeRun in China}

Among all active social platforms, WeChat is the most popular communication facility in China nowadays, which owns 30 percent active users in the market, which exceeds 5 percent than the second one Sina Weibo [1]. Developed by Tencent and released in 2011, WeChat has empowered over 570 million daily active users in China until September 2015 [2].

By creating steps tracking function, WeChat launched WeRun as an official public account to public in 2011. WeRun provides an option for WeChat users with fitness tracker devices or certain phones that can do motion tracking to share the number of steps they take each day and even compete with their friends. WeRun users are able to know exactly how many steps they have taken every day and see how they match up to their friends on WeChat who join WeRun as well. In order to motivate users, WeRun turns the actively data into a social competition with a daily leaderboard, which including all users' WeChat friends who have also opted in. Users are capable to like, share, and publicize their results on moment sharing.

Many studies discussed about the users' functional and 
psychological issues regarding adopting Facebook, Twitter, RenRen, Sina Weibo, etc [3, 4], which are analyzed in the literature review part. However, little research takes WeChat as a study case, not to mention WeRun.

\section{Previous Studies on Continued Use of Social Media}

Different from traditional media, social media is a two-way interaction platform. Users' participation is the first step. Thanks to the popularity of WeChat in China, WeRun gains a stable and big users' base. The continuing participation in online community joint activities helps the community members achieve common goals and is a key factor for community endurance $[5,6]$.

Perceived usefulness is crucial in the study of understanding people's behavioral motivation. U\&G Theory assumes that media users are active in their underlying motivation and explains that people purposely choose certain media in order to gratify their psychological needs [7]. The evaluation of users' motivations of using apps always relates to the rapid development of the Internet. Thus, the convenient Internet service is the pre-conditions of the motivation. The previous research identified the important motivations underlying the use of the Internet including information, convenience, entertainment, and social interaction [8]. Chang and Zhu [9] compared the differences between the pre-adopters and post-adopters on social networking sites in China and found that entertainment motivation has a significant and positive effect on attitudes in the group of pre-adopters and connecting with old friends has a significant and positive influence on the post-adopters' attitudes. In addition, sociality and entertainment are the two dominant motivations. While US college students care about the convenience and information, which the motives of seeking social support and convenience have a significant and positive effect based on Kim et al.'s research [7].

Social Influence and emotional experience play an important role in motivating users. WeRun not only tracks the steps but also provides a wide range of various functionalities, eg. donation, notification, competition, sharing. Such functionalities are called social sharing. Social sharing is the practice of sharing content from a website on a social media site or application. The reason why people like social sharing is all about relationship and engagement that can define oneself to others, to grow and nourish the relationship, to fulfill oneself, and to bring valuable and entertaining content to others. Sharing the amount of steps is a kind of effective way of boosting overall user engagement. Two positive findings have been discussed by Park et al [10]. In their research of users' characteristics who share their health and fitness-related activity on social media outlet over an extend period of time. Firstly, sharing exercise related tweets is positively correlated with the long-term engagement. More frequent to share exercise related posts, more possible to keep long-term engagement. Thus, WeRun's build-in social sharing function might push users to keep engaging. Secondly, having a mutual friendship with those users who share health and fitness related content on social media is positively correlated with persistent social sharing, which means that fitness network is a key element for persistent social sharing. Offering a fitness network, WeRun succeeds to keep users' continuous usage.

On the other hand, peer pressure is important in social influence. June $\mathrm{Lu}$ [11] founds that peer pressure is a key factor in social influence in the research of users' personal innovativeness and social influence critical to continue with e-commerce. The item 'My friend think that I should keep using m-commerce' has a significant influence on mean continuance intention. Such peer pressure is also regarded as consumer discursive power active in social circles [11].

\section{Theoretical Framework}

\subsection{Expectation Confirmation Theory}

Theories explained variances in user intentions mainly include the Social Cognitive Theory, the Use and Gratification Theory, the Motivation Model, the Theory of Reasoned Action, the Theory of Planned Behavior, the Technology Acceptance Model, the Model of PC Utilization, the Diffusion of Innovations Theory. And Studies related to continued use intention focus on exploring the continuous intention and behaviors of users by introducing new variables or different research contexts on the base of the Theory of Expectation Confirmation (ECT).

The ECT originated from consumer behavior study, which was mainly applied in predicting the repeat purchase or usage behaviors of users $[12,13]$. The ECT holds that consumers generate expectation on the product (service) before purchase behavior and generate perceived performance on the product (service) based on actual using experience. Consumers take the degree of confirmation (the results in comparing the expectation before purchase behavior and the perceived performance after purchase behavior) as the criterion to evaluate their satisfaction on the product (service), which will further affect consumers' willingness in repeating purchase or usage.

Bhattacherjee [14] puts forward the expectation-confirmation model of IS continuance (ECM-ISC) based on the expectation confirmation theory (ECT) in the study of sustainable intention of online banking users. Bhattacherjee [14] pointed out that there were many similarities between the sustainable usage of information system by users and repeated purchase 
product (service) by consumers, such as that the two kinds of behaviors both occurred after the initial decision (acceptance or purchase) and were both influenced by the initial use experience. Therefore, the ECT also can explain the continued use of information system. Taking into account the context that information system is used in and the expectation changes of users after accepting information system, Bhattacherjee [14] built a model of continued use of information system ECM-ISC by adding perceived usefulness of Technology Acceptance Model (TAM) [15] into ECT in order to reflect the expectation changes of users after accepting information system. ECM-ISC holds that the continuance intention of users is mainly affected by satisfaction and perceived usefulness, and satisfaction of users is affected by perceived usefulness and recognition degree of expectations.

There are similarities between social media and information system, such as they both are platforms, which provide information services to users by emphasizing interactions with users and users' experiences. But there are significant differences between the two platforms that information system is a relatively closed environment focusing on the technical characteristics of the system itself while social media is an open environment focusing on content properties.

Existing research on social media applications also concern about the adopting and usage. But few give further consideration to the situation that users might abandon the usage of social media applications after adopting it. Although the research based on use and gratification theory involved the continued use of social media applications after users are gratified, it is too narrow to merely attribute the influence factors for users to continuously use social media applications to the gratification of users. Based on this situation, this research tries to explore the continued use factors of social media applications with purpose of making up for the deficiencies in the field of continued use of social media applications.

Combing with the theoretical logic of ECM-ISC, the emotional pleasure of users in using WeRun influences both the continuance intention and the satisfaction. And the confirmation level affecting the emotional pleasure to some extent works as the confirmation process of the expectation should also include the confirmation of the emotional expectation.

\subsection{Emotional Pleasure and Continuance Intention}

ECM-ISC regards satisfaction as the most important factor that affects the continued use of information systems. Although many empirical studies have confirmed this point of view, this study argues that, ECM-ISC provides too simple and general consideration on the psychological factors that influence the continuance intention of users only, which could not comprehensively and specifically reflect various factors affecting the continued use of users.

Norman [16] firstly put forward the concept of 'user experience' that referred to all aspects of the users' interaction with the products and services provided by companies, and the excellent user experience was required to meet and even exceed the basic needs and expectations of users and trigger feelings of pleasure of user, which reflects that the core element of concept of user experience cannot be separated from users' cognition and emotion. Then Mahlke [17] claimed that two types of elements constituted user experience: cognitive experience and emotional pleasure. The cognitive experience, such as decision-making behavior, was obviously influenced by emotional pleasure. It is also found the various kinds of emotional pleasure, such as pleasure, flow and peak, play significant role in user experience [18].

The reason that people use the sport-related application continuously might because of emotional pleasure that those users begin to desire in getting special rewards [19]. It is shown that people may want to get 'good feeling', 'sense of achievement, 'sense of triumph' and other similar rewards when doing exercises. The indication of sport-related applications lies in triggering not only the habitual exercise behavior of users but also users' desire for upcoming sports rewards. The rewards of using sport-related applications have various expressions. Such as, getting 'click a like' from others through posting photos or showing movement steps, sense of fluency due to the increasing secretion of endorphin and dopamine, etc. Users' eager for expected rewards will appear stronger when they are thinking about the upcoming 'sense of achievement' and 'good feeling', which pushes users to use the sport-related applications continuously and keep doing exercises every day.

Thus, this study attempts to develop a new variable emotional pleasure - to investigate the influence of emotional requirements on continuance intention of users. This not only makes up for the lack of the traditional ECM-ISC when considering users' psychology but also makes an exploration on the continued use of social media.

\subsection{Subjective Norm and Continuance Intention}

Use and gratification reflects the continuous usage of users based on the using experience of users. But in real life, people choose to use some social media applications because of its wide popularities in public rather than their urgent needs, which imply that the external environment can make users to take the usage action as well.

The concept of subjective norm originates from the theory of planned behavior (TPB) and the theory of reasoned action (TRA), referring to the social pressures that individuals feel in performing particular acts, namely the pressure from the persons or groups who are important 
to the individuals in agreeing or disagreeing with the individuals to take particular acts [20]. Subjective norm can be measured though two dimensions of interpersonal influence (normative influence) and external influence (influence from information), in which the interpersonal influence refers to the impact of interpersonal communication on individuals in taking an act while the external influence refers to impact of mass media on individuals in taking an act.

The influence of subjective norm in continued use of information system has been verified in some research [21, 22]. However, whether subjective norm can influence on the continued use of social media applications, especially whether the interpersonal influence and the external influence have the same effects, is still need to be tested.

\subsection{Research Hypotheses and Model to be Tested}

Based on the above theoretical framework and new factors introduced, the hypotheses of the research are designed as following:

H1: Confirmation is positively related to emotional pleasure.

H2: Emotional pleasure is positively related to satisfaction.

H3: Emotional pleasure is positively related to continuance intention.

H4: Emotional pleasure mediates the relationship between confirmation and satisfaction.

H5: Emotional pleasure mediates the relationship between confirmation and continuance intention.

H6: Subjective norm is positively related to continuance intention.

H6a: Internal influence is positively related to continuance intention.

H6b: External influence is positively related to continuance intention.

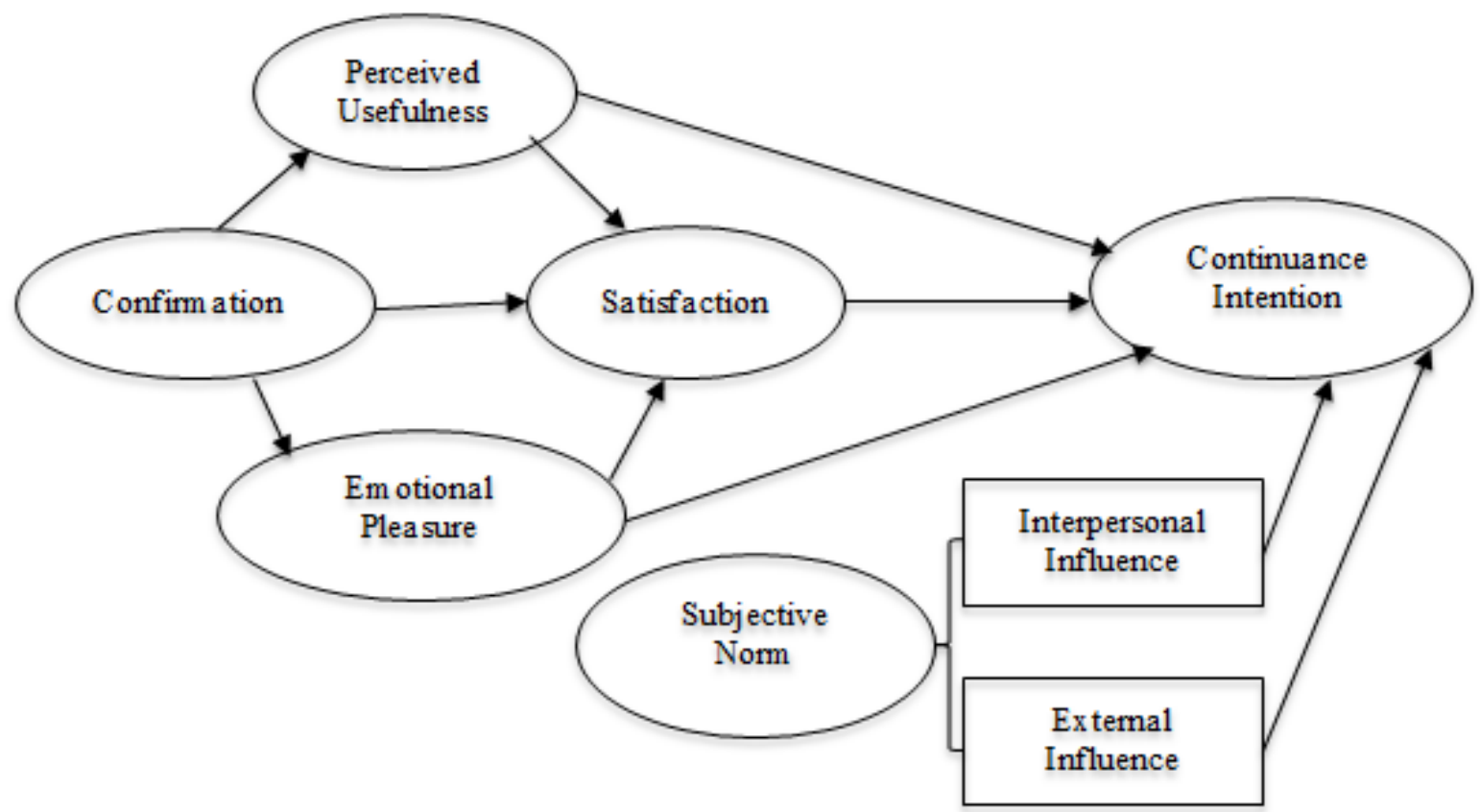

Figure 1. Integrated conceptual model of continuance intention of sport-related application 
Based on the above hypothesis, the research is implemented according to the integrated model shown. The research mainly focuses on testing the variables of emotional factors and subjective norm, the perceived usefulness which has been tested in the ECM-ISC model will also be listed in order to keep the integrity of the model.

\section{Research Design}

This research utilizes survey with online questionnaire put on Sojump. The measurements of relevant variables involved in this study are as follows.

Emotional pleasure refers to the feelings and emotions people receive when using WeRun. Kendzierski and DeCarlo's scale [23] is used to measure this variable, which include five questions. The Cronbach a of the variable Emotional pleasure in this research is 0.877 . The items include: Using WeRun could relieve my anxiety and irritable mood; I feel pride when my steps record ranking the top on WeRun; I consciously refresh my steps records for WeRun ranking; Using WeRun could bring me sense of achievement; Using WeRun makes me feel happy.

Subjective norm refers to the social pressure that users receive when deciding if use WeRun or not. Bhattacherjee's scale [14] is used to measure this variable. The subjective norm is mainly constituted of two sections including internal influence and external influence. The Cronbach $\square$ of the variable internal influence and external influence in the research is separately 0.905 and 0.891 . The items include: My family members/colleagues/friends are using WeRun; My family members/colleagues/friends think I should use WeRun; The people I know think that using WeRun is a good decision; The people I know have positive influence on me in using WeRun; The media reports related to WeRun have positive influence on me in using it; The advertisements related to WeRun have positive influence on me in using it; The expert opinions on WeRun have positive influence on me in using it; The popularity of WeChat stimulates me in using WeRun.

Satisfaction refers to users' evaluation after using WeRun. This variable is measurable by the scale put forward by Hsu et al [24], which includes three questions. The Cronbach $\square$ of the variable satisfaction in this research is 0.951 . The items include: Using WeRun makes me feel satisfied; I like to use WeRun; for me, the use of WeRun is a good decision.

Degree of confirmation of expectations refers to the gap between the real usage situation of users and users' expectation. The scale proposed by Limayem [25] is used to measure this variable, which includes four questions. The Cronbach a of the variable confirmation in this research is 0.952 . The items include: The function provided by WeRun meets my expectation; The Emotional pleasure I acquire in using WeRun meets my expectation; the various services provided by WeRun bring me greater benefits than what I expected; Overall, WeRun meets the majority of my expectation.

Continuance intention refers to users' intention (possibility) of continuous usage of WeRun. This variable is also measured by the scale that put forward by Hsu et al [24], which includes three questions. The Cronbach a of the variable continuance intention in this research is 0.979 . The items include: I am willing to continuously use WeRun; I am going to continuously use WeRun; I will often use WeRun in the future.

Perceived usefulness refers that users think WeRun is beneficial to use. Davis's scale [15] is used to measure this variable, which includes four questions. The Cronbach a of the variable perceived usefulness in this research is 0.858 . The items include: Using WeRun can accurately record my steps every day; Using WeRun is helpful in stimulating me to walk more; Using WeRun is helpful for me to have more knowledge of welfare projects; Using WeRunis helpful in improving my interaction with friends through 'click a like'.

The online questionnaire includes 32 questions with two sections. The first section is about the usage situation of Werun, and the second section is about demographic information. Five-points Likert scale is used in the questionnaire of the first section, which 1 equals to strongly disagree and 5 equals to strongly agree.

\section{Results}

\subsection{Descriptive Statistics}

The online questionnaire was put on Sojump during 4th March to 11th March. The link of the online questionnaire could be available both on computers and smart on smart phones. 498 respondents joined the survey, and 325 (65.3\%) respondents who use WeRun finished the whole questionnaire. Among the WeRun users, those with age between 18 to 30 years old occupied nearly half $(49.85 \%$, $\mathrm{N}=325$ ) of the sample population, and those with age between 31 to 43 years old occupied 28.31\% ( $\mathrm{N}=325)$ of the sample population. There were $138(42.46 \%, \mathrm{~N}=325)$ male respondents and $187(57.54 \%, \mathrm{~N}=325)$ female respondents. The number of respondents with education level of undergraduate and above was 240 (73.84\%, $\mathrm{N}=325$ ). According to the descriptive statistical analysis, there were relatively higher scores on the variables of perceived usefulness $(\mathrm{M}=3.50)$, internal influence $(\mathrm{M}=3.54)$, satisfaction $(\mathrm{M}=3.54)$, and continuance intention ( $M=3.76)$. The descriptive statistics of the sample is summarized in Table 1 and Table 2. 
Table 1. Sample descriptive statistics of latent variables

\begin{tabular}{|c|c|c|}
\hline Variable & Mean & Cronbach a \\
\hline Emotional pleasure & 3.30 & 0.877 \\
\hline $\begin{array}{c}\text { Pride } \\
\text { Happy } \\
\text { Victory } \\
\text { Release } \\
\text { Consciously freshing steps }\end{array}$ & & \\
\hline Internal influence & 3.54 & 0.905 \\
\hline $\begin{array}{c}\text { Friends/relatives use it } \\
\text { Friends/relatives suggest it } \\
\text { Friends/relatives approve it } \\
\text { Positive affect } \\
\end{array}$ & & \\
\hline External influence & 3.10 & 0.891 \\
\hline $\begin{array}{l}\text { Media propaganda } \\
\text { Ad propaganda } \\
\text { Expert suggestion } \\
\text { Popularity of WeRun } \\
\end{array}$ & & \\
\hline Expectation of Confirmation & 3.32 & 0.952 \\
\hline $\begin{array}{l}\text { Usefulness confirm } \\
\text { Emotion confirm } \\
\text { Benefit confirm } \\
\text { Overall confirm } \\
\end{array}$ & & \\
\hline Satisfaction & 3.54 & 0.951 \\
\hline $\begin{array}{l}\text { Satisfy } \\
\text { Like } \\
\text { Good idea } \\
\end{array}$ & & \\
\hline Continuance intention & 3.76 & 0.979 \\
\hline $\begin{array}{c}\text { Will use } \\
\text { Do use } \\
\text { Often use } \\
\end{array}$ & & \\
\hline Perceived usefulness & 3.5 & 0.858 \\
\hline $\begin{array}{c}\text { Recording steps } \\
\text { Stimulating walk } \\
\text { Providing charity information } \\
\text { Promoting interaction }\end{array}$ & & \\
\hline
\end{tabular}

$\mathrm{N}=325$

\subsection{Correlation and Multiple Regression}

The pairwise correlations among variables were investigated using Pearson product-moment correlation coefficient. It was found that there was strong, positive pairwise correlations among the two variables of perceived usefulness and emotional pleasure $(r=.803$, $\mathrm{p}<.01$ ), two variables of perceived usefulness and internal influence $(\mathrm{r}=.771, \mathrm{p}<.01)$, two variables of perceived usefulness and external influence $(\mathrm{r}=.700, \mathrm{p}<.01)$, two variables of perceived usefulness and expectation of confirmation $(\mathrm{r}=.772, \mathrm{p}<.01)$, two variables of perceived usefulness and satisfaction $(\mathrm{r}=.790, \mathrm{p}<.01)$, two variables of perceived usefulness and intention $(\mathrm{r}=.744, \mathrm{p}<.01)$, two variables of emotional pleasure and internal influence $(r=.780, p<.01)$, two variables of emotional pleasure and external influence $(r=.778, p<.01)$, two variables of emotional pleasure and confirmation $(\mathrm{r}=.808, \mathrm{p}<.01)$, two variables of emotional pleasure and satisfaction $(r=.790$, $\mathrm{p}<.01$ ), two variables of emotional pleasure and intention $(\mathrm{r}=.70, \mathrm{p}<.01)$, two variables of internal influence and external influence $(\mathrm{r}=.704, \mathrm{p}<.01)$, two variables of internal influence and confirmation $(\mathrm{r}=.764, \mathrm{p}<.01)$, two variables of internal influence and satisfaction $(\mathrm{r}=.809$, $\mathrm{p}<.01$ ), two variables of internal influence and intention $(r=.786, p<.01)$, two variables of external influence and confirmation $(\mathrm{r}=.813, \mathrm{p}<.01)$, two variables of external influence and satisfaction $(\mathrm{r}=.718, \mathrm{p}<.01)$, two variables of external influence and intention $(\mathrm{r}=.612, \mathrm{p}<.01)$, two variables of confirmation and satisfaction $(\mathrm{r}=.868, \mathrm{p}<.01)$, two variables of confirmation and intention $(\mathrm{r}=.759$, $\mathrm{p}<.01)$, two variables of satisfaction and intention ( $\mathrm{r}=.883$, $\mathrm{p}<.01$ ). Therefore, higher levels of any variable associated with higher levels of the other variables.

Table 2. Sample descriptive statistics of demographic information

\begin{tabular}{|c|c|c|}
\hline Variable & $\mathrm{n}$ & $\%$ \\
\hline Age(years) & & \\
\hline Below than 18 & 0 & 0 \\
\hline $18-30$ & 162 & 49.9 \\
\hline $31-43$ & 92 & 28.3 \\
\hline $44-56$ & 57 & 17.5 \\
\hline 56 and above & 14 & 4.3 \\
\hline Gender & & \\
\hline Male & 138 & 42.5 \\
\hline Female & 187 & 57.5 \\
\hline Education & & \\
\hline Below undergraduate & 85 & 26.1 \\
\hline Undergraduate & 181 & 55.7 \\
\hline Master and above & 59 & 18.2 \\
\hline Occupation & & \\
\hline Students & 46 & 14.1 \\
\hline Managers & 34 & 10.5 \\
\hline Clerk & 43 & 13.2 \\
\hline Professionals & 47 & 14.5 \\
\hline Business/service & 46 & 14.1 \\
\hline Agriculture & 0 & 0 \\
\hline Production/operation & 2 & 0.62 \\
\hline Soldiers & 2 & 0.62 \\
\hline Others & 32.3 \\
\hline
\end{tabular}

$\mathrm{N}=325$

We proceed to test the multiple linear regressions between dependent and independent variables. We firstly used multiple linear regressions of SPSS to separately test the regressions of satisfaction on confirmation, perceived usefulness and emotional pleasure. Tests for multicollinearity indicated that a very low level of multicollinearity was present (Tolerance $=.312$, VIF $=3.21$ for perceived usefulness; Tolerance $=.268$, VIF $=3.73$ for emotional pleasure; Tolerance $=.304$, VIF $=3.29$ for confirmation). It is found that the regressions of satisfaction on emotional pleasure is $\operatorname{significant}(\beta=0.131$, $\left.\mathrm{p}<0.01, \mathrm{R}^{2}=0.794\right)$. Thus, the hypothesis 2 is supported, that the stronger emotional pleasure is, the higher level of satisfaction the users have. 
Table 3. Multiple linear regression

\begin{tabular}{|c|c|c|c|c|}
\hline Variable & R2 & $\beta$ & Tolerance & VIF \\
\hline Satisfaction &. $\mathbf{7 9 4}$ & & .312 & 3.21 \\
\hline Perceived usefulness & & $.241^{* * *}$ & .268 & 3.73 \\
\hline Emotional pleasure & & $.131^{* *}$ & .304 & 3.29 \\
\hline Confirmation of expectation & & $.572^{* * *}$ & & 3.64 \\
\hline Continuance intention & $\mathbf{. 8 0 3}$ & & .275 & 4.31 \\
\hline Perceived usefulness & & $.121^{*}$ & .232 & 3.97 \\
\hline Emotional pleasure & & -.080 & .252 & 3.65 \\
\hline Satisfaction & & $.776^{* * *}$ & .274 & 2.79 \\
\hline Internal influence & & $.251^{* * *}$ & & .358 \\
\hline External influence & & $-.102^{*}$ & & \\
\hline Emotional pleasure & $\mathbf{. 6 5 3}$ & & & \\
\hline Confirmation of expectation & & $.811^{* * *}$ & & \\
\hline
\end{tabular}

${ }^{*} \mathrm{p}<0.05,{ }^{* *} \mathrm{p}<0.01,{ }^{* * *} \mathrm{p}<0.001$.

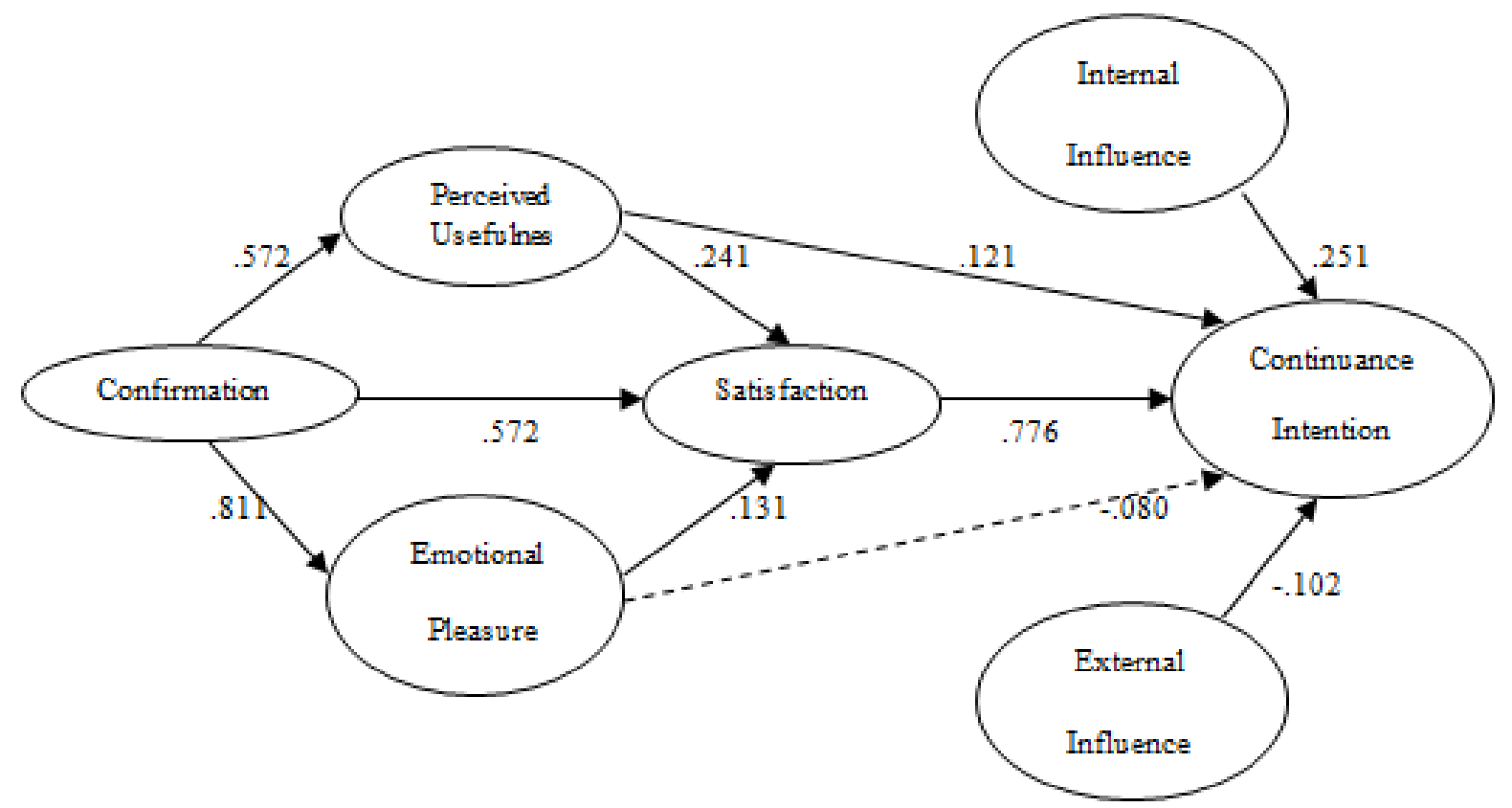

Figure 2. Satistical model of continuance intention of WeRun

We secondly used multiple linear regressions of SPSS to separately test the regressions of continuance intention on perceived usefulness, emotional pleasure, satisfaction, internal influence and external influence. Tests for multicollinearity indicated that a very low level of multicollinearity was present (Tolerance $=.275$, VIF $=3.64$ for perceived usefulness; Tolerance $=.232$, VIF $=4.31$ for emotional pleasure; Tolerance $=.252$, VIF $=3.97$ for satisfaction; Tolerance $=.274$, VIF $=3.65$ for internal influence; Tolerance $=.358$, VIF $=2.79$ for external influence). It is found that the regressions of continuance intention on internal influence $(\beta=0.251, \mathrm{p}<0.001)$ and external influence $(\beta=-0.102, \quad p<0.05)$ are both significant $\left(R^{2}=0.803\right)$, but the regression of continuance intention on emotional pleasure $(\beta=-.080, \mathrm{p}=0.136>0.05)$ is not significant. Thus, the hypothesis 6a is supported, that the greater the internal influence is, the stronger continuance intention the users have. Meanwhile, the hypothesis 3 is rejected, that the higher level of emotional pleasure may not lead to higher degree of continence intention; and the hypothesis $6 \mathrm{~b}$ is rejected, that the greater the external influence is, the weaker continuance intention the users have.

We thirdly used the multiple linear regressions to test the regression of emotional pleasure on confirmation. It is found that the regression of emotional pleasure on confirmation is significant $\left(\beta=0.811, \mathrm{p}<0.001, \mathrm{R}^{2}=0.653\right)$. Thus, the hypothesis 1 is supported, that the higher the confirmation level is, the stronger emotional pleasure the users have. The multiple linear regressions among 
variables are summarized in Table 3 and the statistical model is shown in figure 2 .

\subsection{Mediation Effects}

The research used Mplus to conduct a two-step structural equation modeling [26] to test the mediation effects of the variables proposed in the hypotheses. In the first step of the measurement phase, we analyzed all the measurement items of the measurement phase and checked for correlated residuals and cross-loadings, and excluded two items with high residual variances in one variable. In the second step of the structural phase, we applied the final confirmatory model to test the proposed structural model. In the model fit information, the Chi-square value $\mathrm{X}^{2}(111)=460.182$, the Root Mean Square Error of Approximation (RMSEA) $=0.098<0.10$, the Comparative Fit Index (CFI) $=0.95 \geq 0.95$, and the Root Mean Square Residual (SRMR) $=0.043 \leq 0.06$, so the model produced in this study reached good data-model fits, and the model was examined as initially specified without any changes.

We followed the nested model (excluding the two variables of internal and external influence that were not in the nested model) test procedure and SEM approach to test the existence and the extent of the mediation effects. According to the STDYX Standardization data, the indirect effect from the confirmation to satisfaction via emotional pleasure $(\beta=0.856, \mathrm{p}<0.001)$ is significant, thus the hypothesis 4 is supported, that emotional pleasure acts as a mediator between confirmation and satisfaction. However, the indirect effect from confirmation to continuance intention via emotional pleasure $(\beta=-0.594$, $\mathrm{p}=0.266$ ) is not significant, thus the hypothesis 5 is rejected, that emotional pleasure does not act a mediator between confirmation and continuance intention. The mediation effects of variables are summarized in Table 4.

Table 4. Mediation effects of emotional pleasure

\begin{tabular}{|c|c|c|}
\hline Variable & $\beta$ & S.E. \\
\hline Satisfaction & & \\
\hline Emotional pleasure & & \\
\hline Confirmation of expectation & $0.856^{* * *}$ & 0.172 \\
\hline Continuance intention & & \\
\hline Emotional pleasure & & \\
\hline Confirmation of expectation & -0.594 & 0.533 \\
\hline
\end{tabular}

${ }^{*} \mathrm{p}<0.05,{ }^{* *} \mathrm{p}<0.01,{ }^{* * *} \mathrm{p}<0.001$.

$\mathrm{X}^{2}(111)=460.182, \mathrm{RMSEA}=0.098, \mathrm{CFI}=0.95, \mathrm{SRMR}=0.043$.

\section{Discussion}

The study firstly proves the expectation-confirmation model of IS continuance that confirmation of a product in meeting the expectation would make consumers perceive and recognize the usefulness and function of the product which further leads to consumers' satisfaction of the product and intention in continuously purchasing or using the product. Thus, perceived usefulness is a confirmed factor that would certainly lead to consumers' satisfaction of a social media application.

The creation of this research lies in testing two factors of emotional pleasure in terms of its effect in influencing consumers' satisfaction and continuous intention of using a social media application as well as subjective norm including internal and external aspects in terms of their effects in influencing consumers' continuous intention.

The study shows that users' satisfaction becomes stronger when they feel more emotional pleasure in using the application such as feeling pride and happy when ranking the top, meanwhile, when people confirm their expectations after accepting using WeRun, the more emotional pleasure users feel, the more satisfaction on the application they will have, which the findings are consistent with the previous study that people doing exercises may lie on the reasons of getting good feeling, sense of achievement, sense of victory or similar kinds of rewards [19]. This finding indicates that, besides functional usefulness, when meeting the satisfaction of using a social media application, people pay much attention on whether owing or using this application could bring a sense of pleasure or achievement. Social media application reflects the characters of social habits of users to some extent. Users would like to show others their capacity in doing exercises to get phrase or admiration from others, and the positive mental activity and sense of pleasure is what make users feel satisfied of owing a product.

However, it is shown that emotional pleasure has no significant influence on the continuance use intention of WeRun. The reasons might be drawn from several aspects. Firstly, as one's health status can be easily collected and shared on social media with the prevalence of mobile and wearable devices [10], people may drop to use WeRun when they are afraid of the possibility of being laughed by others or feel peer pressure if they rank behind others or even at the bottom with few daily steps which means they are lazy in doing exercises. Secondly, in accordance with the study of An et al [27] that application of fitness-aids mobile tools were the future trend and effective means for exercising stimulating health, users may be most concerned on the original intention of using WeRun to stimulate themselves in doing exercises in order to improve health rather than focusing on emotions of getting sense of victory or vanity; thirdly, due to the possibility of based measurement [28], people may be reluctant to admit their real psychological situation especially vanity or rivalry when doing self-report questionnaires, fourthly, people might feel tired if they have to walk for a long way every day in order to keep a high rank, thus they may abandon WeRun after use it for a 
period.

The study also shows that people have more continuance intention in using WeRun when they get more positive influence from their friends or family members, which is consistent with the existing studies that the social influence works on continuance intention and the sociality effects from interpersonal communication determine users' trusts and attitudes [8, 29, 30, 31]. In addition, the agreement and suggestions from sounding people have an important impact to encourage users to continuously use WeRun properly because the users' group-following psychology or their willing to join the same living circle with friends and relatives to get more interactions. According to Kelman [32], the effects of social influence fall into three broad categories and two of which are compliance (people appear to agree with pothers), the social influence from interpersonal communication on WeRun could also be reflected through the suggestions and encouragement from family members or friends of users to use WeRun. Meanwhile, people may build up a long-term relationship with friends through WeRun platform's daily steps ranking among friends [5]. Social media application has its social attribute that using WeRun is a behavior under observation by others through social network to some extent. A top ranking every day with means of good exercise capacity and habit of a person can be show off to friends and relatives, while a bottom grade on the WeRun list may make a person being interpreted as a lazy one.

However, the negative influence of external influence on the continuous use intention of WeRun implies that users may drop to use WeRun when they receive too much information from media propaganda or suggestions from experts. Meanwhile, the increasing popularity of WeChat may also lead to users' abandon of WeRun. The reason might lie in that frequent receiving of news or information on WeRun make the user feel their personal behavior or habits are exposed to the public that they may not familiar with [10]. The other assumed reason is that people might not want to use something with the same style with others because of the pursuit of personality.

Furthermore, it is found in this study that emotional pleasure mediates the relationship between confirmation and satisfaction, which indicates that users' confirmation of a social media application in meeting the expectation would be transferred to users' satisfaction of using this application when consumers feel sense of pleasure or cheerful mood through using this application. This finding proves again the importance of emotional pleasure in affecting people's attitude and evaluation to a social media application. However, the mediating processes from confirmation to continuance intention via emotional pleasure is not significant, which means that the positively significant effect of emotional pleasure on continuance intention could be reflected only in the case that the other factors do not play a role. The reason for the situation may lie in that the emotional pleasure can bring mental satisfaction and then promote the continuance intention, but when taking into account more factors such as confirmation of expectation or perceived usefulness, the function of emotional pleasure is replaced by or included in these factors.

\section{Conclusion and Suggestion for Future Research}

WeRun is popular in Chinese, especially the young adults. WeRun is not only a software of smart phone for recording the daily steps, but also an application which providing various functions besides simple count and stimulating positive emotion of users. This research aims to explore the factors that contribute to the continuance use intention of WeRun.

Based on ECM-ISC model, this study tried to construct an integration model of continuance use intention of sport-related application including perceived usefulness, satisfaction, emotional pleasure and subjective norm (internal and external influences) in order to explore various factors influencing the continued use of sport-related application. In the integration model, perceived usefulness, emotional pleasure and satisfaction stand for the initiative factors belong to the cognitive dimension of continuance intention of users, while the subjective norm (including internal and external influences) stands for the passive factors affecting the continuance intention of users. In the phase of continued use, both the initiative and passive could have impacts on continuance intention of users.

As the factors that influence the continuance use intention and behavior of social applications are very complex, in addition to the factors revealed in this study, other factors such as user preferences and functions related to social media platform or smart phones may also affect the continuance use intention of users.

We suggest that more factors should be taken into account and tested gradually to implement the integration model in order to improve the theoretical model of continuance intention based on confirmation and satisfaction. In addition, the study only explored the intention of Chinese users in using social application, and the attitudes and intention of users of other countries should also be included in studying the continuance intention of social application. Furthermore, as the main targets of social media, especially sports related social applications, are young people, the characteristics of young people and differences among various groups of people in different age in using social application should also be taken into account in the future research. 


\section{Acknowledgements}

This paper thanks Prof. Dominic Yeo of School of Communication, Hong Kong Baptist University very much for his kind guidance and support.

\section{REFERENCE}

[1] We Are Social (January, 2015), “Digital, Social, and Mobile Report”, available at

http://wearesocial.com/uk/special-reports/digital-social-mo bile-worldwide-2015 (accessed 25 January, 2016).

[2] China Internet Watch (November, 2015) "WeChat Daily Active Users Reached 570 Mln in Sept 2015”, available at http://www.chinainternetwatch.com/15287/wechat-users-in sights-2015/ (accessed 1 January, 2016).

[3] Yang, C., \& Srinivasan, P. (2016). Life satisfaction and the pursuit of happiness on twitter: E0150881. PLoS One, 11(3).

[4] Greenwood, D. N. (2013). Fame, Facebook, and Twitter: How attitudes about fame predict frequency and nature of social media use. Psychology of Popular Media Culture, 2(4), 222-236.

[5] Koh, J., \& Kim, D. (2004). Knowledge sharing in virtual communities: an e-business perspective. Expert Systems with Application, 26, 155e166.

[6] Agag, G., \& El-Masry, A. A. (2016). Understanding consumer intention to participate in online travel community and effects on consumer intention to purchase travel online and WOM: An integration of innovation diffusion theory and TAM with trust. Computers in Human Behavior, 60, 97-111.

[7] Kim, Y., Sohn, D., \& Choi, S. M. (2011). Cultural difference in motivations for using social network sites: A comparative study of American and Korean college students. Computers in Human Behavior, 27(1), 365-372.

[8] Lien, C. H., \& Cao, Y. (2014). Examining WeChat users' motivations, trust, attitudes, and positive word-of-mouth: Evidence from china. Computers in Human Behavior, 41, 104-111.

[9] Chang, Y. P., \& Zhu, D. H. (2011). Understanding social networking sites adoption in China: A comparison of pre-adoption and post-adoption. Computers in Human Behavior, 27(5), 1840-1848.

[10] Park, K., Weber, I., Cha, M., \& Lee, C. (2015). Persistent sharing of fitness app status on twitter. Proceedings of the 19th ACM Conference on Computer-Supported Cooperative Work \& Social Computing, 184-194.

[11] Lu, J. (2014). Are personal innovativeness and social influence critical to continue with mobile commerce?, Internet Research, 24(2), 134-159.

[12] Oliver, R. L. (1977). Effect of expectation and disconfirmation on post exposure product evaluations - an alternative interpretation. Journal of Applied Psychology, 62(4), 480.
[13] Oliver, R. L. (1980). A cognitive model of the antecedents and consequences of satisfaction decisions. Journal of Marketing Research, 17(4), 460.

[14] Bhattacherjee, A. (2000). Acceptance of e-commerce service: the case of electronic brokerages, System, Man and cybernetics, Part A: System and humans, IEEE Transactions, 30 (4), 411-420.

[15] Davis, F. D. (1989). Perceived usefulness, perceived ease of use, and user acceptance of information technology. MIS Quarterly, 13(3), 319-340.

[16] Norman, D.A. (1998). The psychology of everyday things. New York: Basic books.

[17] Mahlke, S. (2005).Understanding users' experience of interaction. In Proc. of the 2005 Annual Conference on European Association of Cognitive Ergonomics. ACM International Conference Proceeding Series, 132, 251-254. University of Athens.

[18] Norman, D.A. (2004). Introduction to this special section on beauty, goodness, and usability. Human-Computer Interaction, 19(4), 311-318.

[19] Duhigg, C. (2012). The power of habit: Why we do what we do in life and business. New York: Random House.

[20] Dubinsky, A.J. \& Loken, B. (1989). Analyzing ethical decision making in marketing. Journal of Business Research, 19(2), 83-107.

[21] Hung, S. Y., Chang, C.M., \& Yu, T. (2006). Determinants of user acceptance of thee-Government services: The case of online tax filing and payment system. Government Information Quarterly, 23(1), 97-122.

[22] Hung, S. Y., Tang, K.Z., Chang, C.M. \& Ke, C.D. (2009). User acceptance of intergovernmental services: An example of electronic document management system. Government Information Quarterly, 26(2), 387-397.

[23] Kendzierski, D., \& DeCarlo, K. (1991). Physical activity enjoyment scale: Two validation studies. Journal of Sport and Exercise Psychology, 13, 50-64.

[24] Hsu, M.H., Yen, C.F., \& Chiu, C.M., (2006). A longitudinal investigation of continued online shopping behavior: An extension of the theory of planned behavior. International Journal of Human-Computer Studies, 64(9), 889-904.

[25] Limayem, M., Hirt, S.G., \& Cheung, C.M.K. (2007). How habit limits the predictive power of intention: the case of information systems continuance. MIS Quarterly, 31, 705-737.

[26] Kline, L.B. (1998). Principles and practice of structural equation modeling. New York, NY: Guilford.

[27] An, N., Yi, M.Q., Qian, J.H., Wang, X.H., \& Li, G.P. (2014). Future trend of exercise improving health: A view of the ACSM's 61st annual meeting. Journal of Beijing Sport University, 37 (8), 60-64.

[28] Connell, A., \& Farrington, D.P. (1996). Bullying among incarcerated young offenders: Developing an interview schedule and some preliminary results. Journal of Adolescence, 19(1), 75-93.

[29] Venkatesh, V. and Davis, F.D. (2000). A theoretical 
extension of the technology acceptance model: Four longitudinal field studies, Management Science, 46 (2), 186-204.

[30] Cheung, M.K. and Lee, M.K. (2009). Understanding the sustainability of a virtual community: Model development and empirical test. Journal of Information Science, 35 (3), 279-298.
[31] Wang, J.C. and Chiang, M.J. (2009), Social interaction and continuance intention in online auctions: a social capital perspective. Decision Support Systems, 47 (4), 466-476.

[32] Kelman, H. (1958). Compliance, identification, and internalization: three processes of attitude change, Journal of Conflict Resolution, 1 (1), 51-60. 